\title{
Do long- and short-winged adult females of the bug Pyrrhocoris apterus (Heteroptera: Pyrrhocoridae) differ in lifespan and reproductive capacity?
}

\author{
RADOMÍR SOCHA
}

\author{
Biology Centre ASCR, Institute of Entomology, Branišovská 31, CZ-370 05 České Budějovice, Czech Republic; \\ e-mail: socha@entu.cas.cz
}

Key words. Heteroptera, Pyrrhocoridae, Pyrrhocoris apterus, firebug, females, wing morphs, lifespan, reproductive capacity

\begin{abstract}
In the present study we tested whether long-winged (macropterous) and short-winged (brachypterous) adult females of the firebug Pyrrhocoris apterus (L.) differ in their reproductive capacity and length of life. The following seven physiological markers were measured in these females: lengths of the pre-oviposition period (pre-OP), inter-ovipositon period (inter-OP) and postoviposition period (post-OP), and the mean number of eggs per batch, total number of eggs, mean total number of egg batches laid and lifespan of the females. The results showed that macropterous and brachypterous females significantly differed in the length of the pre-OP, which was significantly shorter in brachypterous ( $7.95 \pm 1.75$ days) than in macropterous females (26.84 \pm 9.86 days), but there was no significant difference between the lengths of the inter-OP in brachypterous (4.00-8.79 days) and macropterous (3.00-9.89 days) females. In contrast the length of the post-OP was significantly longer in brachypterous (48.23 \pm 30.95 days) than in macropterous females $(35.02 \pm 17.32$ days). Except for the 2 nd and $3 \mathrm{rd}$ egg batches there was no significant difference between the average numbers of eggs in the other egg batches laid by females of the two wing morphs. Total number of eggs laid by macropterous females during their whole lifespan was not significantly lower ( $326.47 \pm 155.65$ eggs) than by brachypterous females ( 382.82 \pm 207.52 eggs), but associated with the lower number of egg batches laid by macropterous (13) than by brachypterous females (19). However, there was no significant difference in the longevity of brachypterous $(95.43 \pm 41.21$ days) and macropterous (93.40 \pm 21.18 days) females. The relationship of these results to the reproductive arrest, inactivity of the endocrine gland, corpus allatum, and different levels of adipokinetic hormone in macropterous females is discussed.
\end{abstract}

\section{INTRODUCTION}

The firebug Pyrrhocoris apterus (L.) is a palaearctic species belonging to the family Pyrrhocoridae (Heteroptera) with a core distribution in the Mediterranean area and eastern and central Asia. In central Europe, the firebug mostly lives at the foot of lime trees (Tilia cordata Miller, T. platyphylos Scopoli) the seeds of which are its main food (Socha, 1993). P. apterus shows conspicuous wing polymorphism and produces macropterous (long-winged) and brachypterous (short-winged) morphs (Honěk, 1976; Socha, 1993). Although the adult macropterous males and females have indirect flight muscles (Socha \& Šula, 2006) they are not capable of flying (Socha \& Zemek, 2000a). Thus, a non-functional wingpolymorphism is a characteristic feature of the firebug (Socha, 1993).

The macropterous adults differ from the brachypterous ones in several biochemical, physiological and behavioural parameters; e.g. in having a longer pre-reproductive period (Honěk, 1985; Socha \& Šula, 1996; Socha, 2006), lower level of glycogen and lipids in the fat body (Socha et al., 1997, 1998), decreased food intake (Socha et al., 1997, 1998; Socha \& Zemek, 2007) and enhanced walking and dispersal ability (Socha \& Zemek, 2000b, 2003), which is associated with a lower and postponed mating activity (Socha, 2004, 2008). The greater walking and dispersal activity of 10 day old macropterous adults of $P$. apterus is positively correlated with a more intensive mobilization of lipids by the adipokinetic hormone
(AKH) (Maxová et al., 2001) and higher levels of AKH in the central nervous system (CNS) and haemolymph (Kodrík et al., 2003). The high level of AKH recorded during the almost 2-3 week long spontaneous fast of adult macropters is associated with flight muscle development (Socha \& Šula, 2006), inhibition of ovarian growth in females (Socha, 2007) and delayed maturation of the accessory glands in males (Socha, 2006). The growth of the reproductive organs in the adults of both brachypterous and macropterous morphs is dependent on juvenile hormone $(\mathrm{JH})$. This was demonstrated by measuring the volume and activity of the corpus allatum (CA), the source of this hormone (Hodková \& Socha, 2006; Socha \& Hodková, 2006), allatectomy or treating adults with an active juvenile hormone analogue ( $\mathrm{JHa})$ - methoprene (Socha et al., 1991, Socha, 2007). This finding indicates that the $\mathrm{JH}$ titre in 1-14 day old macropterous adults that are characteristically in reproductive arrest must be below the threshold needed for stimulating egg production in females and growth of accessory glands in males. It appears therefore, that the increase in the $\mathrm{AKH}$ titre recorded in 5-14 day old macropterous bugs is coupled with the absence or a very low titre of $\mathrm{JH}$ in the body. Decrease in the AKH titre in the CNS and haemolymph in macropterous adults older than 14 days is associated with resumption of food consumption (Socha \& Zemek, 2007), followed by full reactivation of the CA (Hodková \& Socha, 2006) and subsequent flight muscles histolysis 
TABLE 1. The length of the pre-OPs and inter-OPs in brachypterous and macropterous adult females of P. apterus.

\begin{tabular}{cccc}
\hline \multirow{2}{*}{$\begin{array}{c}\text { Pre-OP and inter-OPs between } \\
\text { consecutive egg batches }\end{array}$} & \multicolumn{2}{c}{ Pre-OP and inter-OPs (in days), means \pm S.D $(n)$} & Significance $(P)$ \\
\cline { 1 - 3 } Pre-OP & Brachypterous females & Macropterous females & $P<0.0001(\mathrm{~s})$ \\
$1-2$ & $7.95 \pm 1.75^{*}(40)$ & $26.84 \pm 9.86^{*}(70)$ & $P=0.4036(\mathrm{~ns})$ \\
$2-3$ & $4.41 \pm 1.31(39)$ & $4.66 \pm 1.54(53)$ & $P=0.4431(\mathrm{~ns})$ \\
$3-4$ & $4.97 \pm 2.85(36)$ & $5.42 \pm 3.37(50)$ & $P=0.1489(\mathrm{~ns})$ \\
$4-5$ & $4.66 \pm 1.18(32)$ & $4.96 \pm 4.96(39)$ & $P=0.8212(\mathrm{~ns})$ \\
$5-6$ & $4.74 \pm 1.88(31)$ & $5.65 \pm 3.28(31)$ & $P=0.0704(\mathrm{~ns})$ \\
$6-7$ & $8.79 \pm 8.84(28)$ & $5.88 \pm 1.99(25)$ & $P=0.6067(\mathrm{~ns})$ \\
$7-8$ & $5.44 \pm 3.74(25)$ & $9.89 \pm 10.21(19)$ & $P=0.5185(\mathrm{~ns})$ \\
$8-9$ & $8.04 \pm 7.81(24)$ & $5.58 \pm 1.98(12)$ & $P=0.9392(\mathrm{~ns})$ \\
$9-10$ & $5.50 \pm 3.68(18)$ & $5.56 \pm 1.42(9)$ & $P=0.8850(\mathrm{~ns})$ \\
$10-11$ & $5.67 \pm 2.26(15)$ & $8.33 \pm 5.47(6)$ & $P=0.1430(\mathrm{~ns})$ \\
$11-12$ & $4.40 \pm 1.17(10)$ & $3.00 \pm 1.41(2)$ & $P=0.4504(\mathrm{~ns})$ \\
$12-13$ & $4.29 \pm 1.25(7)$ & $8.00 \pm 4.24(2)$ & $P=0.4663(\mathrm{~ns})$ \\
$13-14$ & $4.50 \pm 2.35(6)$ & & \\
$14-15$ & $5.00 \pm 0.82(4)$ & & \\
$15-16$ & $4.67 \pm 2.08(3)$ & & \\
$16-17$ & $8.50 \pm 4.95(2)$ & & \\
$17-18$ & $4.00(1)$ & & \\
$18-19$ & $5.00(1)$ & & \\
\end{tabular}

Notes: Statistically significant differences at the $5 \%$ level (brachypterous vs. macropterous females) are indicated by asterisks. The numbers in brackets present number of adult females of both wing morphs analysed. Abbreviations: S.D. - standard deviation; $n-$ number of adult females analysed; $\mathrm{s}$ - significant; ns - not significant.

induced by an enhanced titre of $\mathrm{JH}$ in the body (Socha \& Šula, 2006, 2008).

In contrast to the high level of $\mathrm{JH}$ and low titre of $\mathrm{AKH}$ in reproductive brachypterous adult females of $P$. apterus, the greater dispersal activity of 5-14 day old macropterous adults in reproductive arrest is associated with the absence or a very low titre of $\mathrm{JH}$ and high titre of $\mathrm{AKH}$ in the body, while the transition from dispersal to reproduction in macropterous adults older than 14 days is coupled with a change in the levels of these hormones in favour of JH (Kodrík et al., 2003; Hodková \& Socha, 2006). The question is whether the delayed start to oviposition in macropterous females might result in their living longer and changes in some other aspects of their reproductive capacity.

The aim of the present study was therefore to determine whether brachypterous and macropterous females of $P$. apterus differ in the following seven physiological indices: the lengths of the pre-oviposition, inter-oviposition and post-oviposition periods, the average number of eggs in each batch, the total number of eggs laid per female and the mean total number of egg batches laid and their lifespan.

\section{MATERIAL AND METHODS}

\section{Experimental animals}

The laboratory stock culture of $P$. apterus originated from a wild population in České Budějovice, Czech Republic $\left(48^{\circ} 59^{\prime} \mathrm{N}, 1^{\circ} 28^{\prime} \mathrm{E}\right)$. The 5 th generation was used in the present study. All stages from egg to adult were reared under a long-day
(18L : 6D) photoperiod and a constant temperature of $26 \pm 1^{\circ} \mathrm{C}$ at which these bugs breed continuously. Nymphs and adults were kept in glass jars $(0.51)$ in a mass culture (approximately 40 specimens per jar) and supplied with linden seeds and water ad libitum, which was replenished twice a week. The water was supplied in small glass tubes plugged with cotton wool. More details on the maintenance of this culture are described elsewhere (Socha \& Šula 1996; Socha et al., 1997, 1998). Freshly ecdysed adult females of brachypterous and macropterous morphs destined for experiments were transferred individually to Petri dishes (diameter $6 \mathrm{~cm}$ ) and kept without males under the same conditions they developed in until they died. They were supplied with linden seeds and water, which were replenished twice a week.

\section{Experimental analyses}

The length of the pre-oviposition period (pre-OP) was the interval in days between adult emergence and first oviposition. The length of the inter-ovipositon period (inter-OP) was the average interval in days between two successive egg batches, e.g. between the 1 st and 2 nd egg batches, 2 nd and 3 rd, etc. The length of the post-oviposition period (post-OP) was the interval in days from the day of the last oviposition until the death of the female. The average number of eggs per each egg batch was calculated from the numbers of eggs laid by brachypterous or macropterous females in each egg batch. The total number of eggs is the sum of all eggs laid by each experimental adult female of both wing morphs during their whole lifespan. The longevity of each experimental adult female was the time in days from adult emergence until death.

\section{Data presentation and statistical analyses}

Statistical analyses were performed by means of the software GraphPad Prism, version 4.0 (San Diego, CA, U.S.A.). Data on 
TABLE 2. The average number of eggs in consecutive egg batches laid by brachypterous and macropterous adult females of $P$. apterus.

\begin{tabular}{|c|c|c|c|}
\hline \multirow{2}{*}{ No. of egg batch } & \multicolumn{2}{|c|}{ Number of eggs in consecutive egg batches, means \pm S.D $(n)$} & \multirow{2}{*}{ Significance $(P)$} \\
\hline & Brachypterous females & Macropterous females & \\
\hline 1 & $51.05 \pm 10.84(40)$ & $55.46 \pm 12.57(70)$ & $P=0.0659(\mathrm{~ns})$ \\
\hline 2 & $51.03 \pm 15.51 *(39)$ & $57.30 \pm 10.79 *(53)$ & $P=0.0245(\mathrm{~s})$ \\
\hline 3 & $50.56 \pm 15.60 *(36)$ & $56.66 \pm 9.44 *(53)$ & $P=0.0240(\mathrm{~s})$ \\
\hline 4 & $53.44 \pm 14.94(32)$ & $56.84 \pm 9.61(50)$ & $P=0.2129(\mathrm{~ns})$ \\
\hline 5 & $50.68 \pm 14.32(31)$ & $54.41 \pm 9.95(39)$ & $P=0.2036(\mathrm{~ns})$ \\
\hline 6 & $47.71 \pm 16.64(28)$ & $52.29 \pm 10.30(31)$ & $P=0.2041(\mathrm{~ns})$ \\
\hline 7 & $48.12 \pm 13.68(25)$ & $47.64 \pm 12.53(25)$ & $P=0.8976(\mathrm{~ns})$ \\
\hline 8 & $47.25 \pm 17.00$ & $46.11 \pm 12.32(19)$ & $P=0.8073(\mathrm{~ns})$ \\
\hline 9 & $43.56 \pm 15.84(18)$ & $39.67 \pm 19.05(12)$ & $P=0.5482(\mathrm{~ns})$ \\
\hline 10 & $33.67 \pm 20.59(15)$ & $34.22 \pm 20.83(9)$ & $P=0.9503(\mathrm{~ns})$ \\
\hline 11 & $38.80 \pm 16.84(10)$ & $28.33 \pm 16.67(6)$ & $P=0.2469(\mathrm{~ns})$ \\
\hline 12 & $39.00 \pm 16.57(7)$ & $25.00 \pm 14.14(2)$ & $P=0.3181(\mathrm{~ns})$ \\
\hline 13 & $35.33 \pm 19.91(6)$ & $8.00 \pm 8.49(2)$ & $P=0.1204(\mathrm{~ns})$ \\
\hline 14 & $33.50 \pm 19.02(4)$ & & \\
\hline 15 & $33.30 \pm 16.17(3)$ & & \\
\hline 16 & $23.50 \pm 28.99(2)$ & & \\
\hline 17 & $35.00(1)$ & & \\
\hline 18 & $22.00(1)$ & & \\
\hline 19 & $8(1)$ & & \\
\hline
\end{tabular}

Notes: Statistically significant differences at the 5\% level (brachypterous vs. macropterous females) are indicated by asterisks. The numbers in brackets are the number of adult females of both wing morphs analysed. Abbreviations: S.D. - standard deviation; $n-$ number of adult females analysed; s - significant; ns - not significant.

the lengths of the pre-OP, inter-OPs, post-OPs, numbers of eggs in individual egg batches, total number of eggs laid during whole lifespan and the lifespan of brachypterous and macropterous females were compared statistically using a two-tailed $t$ test and one-way ANOVA with Newman-Kuels Multiple Comparison post-test.

\section{RESULTS}

\section{Pre-oviposition, inter-oviposition and post-oviposition periods}

The results show that brachypterous and macropterous adult females substantially differed in the length of their pre-OPs (Table 1$)$. It was significantly $(P<0.0001)$ shorter in brachypterous $(7.95 \pm 1.75$ days $)$ than in macropterous females (26.84 \pm 9.86 days).

On the other hand, there were no significant differences (at the 5\% level) in the lengths of the inter-OPs between consecutive egg batches of adult brachypterous and macropterous females (Table 1). In the brachypterous females the inter-OPs varied from 3.00 to 8.79 days, in macropterous females from 3.00 to 9.89 days. The results show that the postponed oviposition in macropterous females did not influence the interval between consecutive egg batches. Once macropterous females began laying eggs, the lengths of all their individual inter-OPs did not significantly differ from those recorded for brachypterous females.
However, the length of the post-OP was significantly $(P=0.0049)$ shorter in macropterous (35.02 \pm 17.32 days) than in brachypterous females (48.23 \pm 30.95 days).

\section{The average number of eggs per egg batch}

The results are summarized in the Table 2. While the average number of eggs per egg batch for brachypterous females varied from $23.50 \pm 28.99$ to $53.44 \pm 14.94$ eggs, for macropterous females it varied from $8.00 \pm 8.49$ to $57.30 \pm 10.79$ eggs. Except for the 2nd and 3rd egg batches there were no significant differences between the average number of eggs per batch in consecutive egg batches laid by brachypterous and macropterous females during their lifespan.

\section{Total number of eggs laid}

The average total number of eggs laid by brachypterous females during their whole lifespan was $382.82 \pm 207.52$ eggs $(n=40)$ and in macropterous females it was somewhat smaller $326.47 \pm 155.65$ eggs $(n=58)$. This small difference is associated with the higher number of egg batches laid by brachypterous females (19) than by macropterous females (13) during their whole lifespan. Nevertheless, the statistical analysis showed no significant difference between the total number of eggs laid by brachypterous and macropterous females during their whole life. 


\section{Length of life}

The results show that the average length of life of adult brachypterous females was $95.43 \pm 41.21$ days $(n=40)$ and of macropterous females $93.40 \pm 21.18$ days $(n=58)$. The statistical analysis revealed no significant difference between the longevity of adult females of the brachypterous and macropterous morphs. Despite this, adult macropterous females laid fewer batches of eggs (13) than brachypterous females (19).

\section{DISCUSSION}

There are studies on the reproductive potential of macropterous and brachypterous morphs of species of various insects including aphids, corixids, leafhoppers, crickets, gerrids, locusts and others (Harrison, 1980; Roff, 1986; Rankin \& Burchsted, 1992; Zera \& Denno, 1997). Most of these studies show that brachypterous specimens or non-migrants are more fecund than the macropterous or migrant individuals. It is reported that there is a reproductive cost associated with flight capability in some wing dimorphic insects (Harrison, 1980; Zera \& Denno, 1997). The cost of reproduction is usually discussed in terms of the cost of reproduction for females as it is generally and implicitly assumed that the cost for males of producing ejaculates (sperm and male accessory gland secretions) is relatively low.

The present comparative study on $P$. apterus included only virgin brachypterous and macropterous females, since it is known that in many insects, male accessory gland proteins transferred to females during mating reduce female survival, thus constitute a cost of reproduction (Gillot, 2003; Kubli, 2003; Wigby \& Chapman, 2005). However, in some species (e.g. in anthocorid bugs) mating and male accessory gland secretions increase female survival (Kobayashi \& Oskabe, 2009) and there might be several other possible causes of the negative effect of mating on female lifespan (De Loof, 2011). Nevertheless, in P. apterus, an additional (mating independent) cost associated with egg production seems unlikely, because ablating the ovary does not prolong the lifespan of adult females (Hodková, 2008), but additional costs of vitellogenin synthesis and /or other reproduction related processes have not be excluded (Blazkova et al., 2011).

Considering other studies in which the females were not mated, the brachypterous females of the planthopper, Prokelisia dolus Wilson, not only start reproducing earlier but also live twice as long and are over twice as fecund as macropterous females (Denno et al., 1989). Similarly, the lifespan and pre-OP of macropterous females are longer than in brachypterous females in the oriental chinch bug, Cavelerius saccharivorus Okajima (Fujisaki, 1986). In contrast this study of the heteropteran $P$. apterus shows that despite the delayed start to reproduction in macropterous compared to brachypterous females, the lifespans and total number of eggs laid by females of the two wing morphs did not differ significantly. This accords with the study of Honěk (1985) who also did not record differences in the longevity of adult macropters and brachypters in both selected laboratory non-diapause and wild postdiapause specimens of this bug. In addition, no differences are recorded in the fecundity and speed of diapause termination induced by a long-day (18L : 6D) photoperiod and temperature $24^{\circ} \mathrm{C}$ of wild brachypterous and macropterous bugs after transfer from the field to the laboratory. On the other hand, this author records that the average duration of development from egg to adult emergence is significantly longer in macropters than in brachypters in a laboratory strain selected for macropterous production, though in the wild material there is no difference.

The present study demonstrates that the total number of eggs laid by macropterous females of $P$. apterus did not significantly differ from that laid by brachypterous females. The non-significantly lower total number of eggs laid by macropterous females than by brachypterous females is associated with the lower number of egg batches laid by macropterous than by brachypterous females. However, it cannot be excluded that the spontaneous, almost 2-3 week long fasting of macropterous females after adult emergence (Socha et al., 1997, 1998), high titre of the lipid-mobilizing hormone (Pyrap-AKH) in the haemolymph and CNS (Kodrík et al., 2003) and very low activity of the CA associated with a $\mathrm{JH}$ titre below the treshold necessary for oocyte growth (Hodková \& Socha, 2006) might account for the lower total number of egg batches laid by these females than by brachypterous females. It is likely that the level of Pyrap-AKH and CA activity coupled with the production of JH coordinate the enhanced dispersal activity during the fasting after adult emergence, the subsequent histolysis of flight muscles followed by the start of reproduction and the lower total number of egg batches laid by macropterous females of $P$. apterus. However, all these physiological differences are not reflected in the lifespans of macropterous and brachypterous females. It is interesting that the fecundity of the macropters of a cricket is reduced to a much greater degree than that of the brachypters when food is limiting (Tanaka, 1993). Similarly, brachypterous corixids are also more fecund than their macropterous counterparts when food is limiting, but not when the food is abundant (Young, 1965). There is little difference in age at first reproduction when both wing morphs are fed high quality plants (Kisimoto, 1965). In the pond skater Gerris buenoi, a scarcity of food results in a decrease in the rate of oviposition and an increase in longevity (Rowe \& Scuder, 1990), whereas in the water strider Aquarius remigis, it affects fecundity and the pre-OP, but not longevity (Blanckenhorn, 1994). It is also interesting that following extended diapause, brachypters of some planthoppers and water striders are much more fecund than macropters (Fairbairn, 1988).

According to evolutionary theories of ageing, there is a trade off between fecundity and longevity (e.g. Stearns, 1992; Barnes \& Partridge, 2003), but little is known about the regulative physiological mechanisms involved, including the hormones (e.g. Harshman \& Zera, 2006; Flatt \& Kawecki, 2007). Many authors suppose that a 
reduction in reproductive activity increases longevity in many insects (Bell \& Koufopanou, 1986; Partridge \& Barton, 1993; Tatar, 2001, and others). However, new evidence indicates that the tissue-signalling that is mediated by hormones might play an important role in the cost of reproduction (Tatar et al., 2003; Williams, 2005). A pro-ageing effect of $\mathrm{JH}$ is supported by the observation that the surgical removal of the CA, the source of this hormone, prolongs lifespan in acridid grashoppers (Pener, 1972), the monarch butterfly Danaus plexippus (Herman $\&$ Tatar, 2001) and the firebug P. apterus (Hodková, 2008). When the larvae of the mosquito Aedes aegypti are exposed to sublethal concentrations of the $\mathrm{JH}$ analogue methoprene, the longevity of the adult females is significantly reduced (Sawby et al., 1992). These differences in the longevity are also recorded in polyphenic species of insects. The long-winged migrant adults of $D$. plexippus, which have functional flight muscles during reproductive diapauses, are longer lived than non-migrant summer adults, when each are maintained under standard laboratory conditions. The arrested reproductive development of migrant adult males and females is a consequence of suppressed synthesis of JH (Herman \& Tatar, 2001). These authors suggest that longevity in this insect species is regulated by this hormone. The longevity of migrant adults treated with $\mathrm{JH}$ is shortened whereas that of summer adults is increased by $100 \%$ when $\mathrm{JH}$ synthesis is prevented by surgical removal of its source, the CA (Herman \& Tatar, 2001). In contrast, the present study did not reveal any significant difference between the longevity of dispersing macropterous females, in which characteristically CA activity is low and the synthesis of $\mathrm{JH}$ suppressed (Hodková \& Socha, 2006) for almost 2-3 weeks after adult emergence, and that of reproductive brachypterous females in which the $\mathrm{CA}$ is active and the resultant high $\mathrm{JH}$ titre promotes the growth of oocytes almost immediately after the larval-adult ecdysis. These results indicate that the decreased $\mathrm{JH}$ level may not be sufficient to increase lifespan, which is also supported by the finding that homozygous InR mutants of Drosophila melanogaster, which have a reduced level of $\mathrm{JH}$, do not have a longer lifespan (Tatar et al., 2001). However, surgical experiments on brachypterous females of $P$. apterus (Hodková, 2008) demonstrate that the lifespan and reproduction of these females are linked with signals from the pars intercerebralis of the brain and the CA, and contrary to the widely held view, neither the production of eggs nor gonad-signalling were costly in terms of female longevity. Recently, it was reported that the CA activity $(\mathrm{JH})$ and sexual interactions significantly reduce the lifespan of both females and males of this bug (Blazková et al., 2011). However, it is unknown how JH controls the lifespan of $P$. apterus. Since ovary-ablation has no effect on the lifespan of intact and allatectomized females of $P$. apterus (Hodková, 2008) and the oxygen consumption of CA-ablated and ovary-ablated females of this bug is similar (Sláma, 1964), it is unlikely that egg production and metabolic rate, which are stimulated by $\mathrm{JH}$ in females of this heteropteran species, are important in determining their longevity.

As mentioned above, unlike similar aged reproducing brachypterous females with active CAs the dispersing flightless macropterous females of $P$. apterus are characterized by a reproductive arrest of non-diapause type as a consequence of inactive CAs and $\mathrm{JH}$ titres below the level inducing egg development (Hodková \& Socha, 2006). However, despite the almost 2-3 week delay in the CA becoming fully active in adult macropterous females, the difference in the activity of this endocrine gland in the two morphs did not significantly affect their longevity or the total number of eggs laid. In contrast to what happens in D. plexippus migrant females, our results show that the longevity of dispersing macropterous females of $P$. apterus, in which reproduction is arrested and delayed, did not differ significantly from that of early reproducing brachypterous females. Although the longevity of macropterous and brachypterous females of $P$. apterus was similar, macropterous females laid only slightly fewer eggs, but not significantly fewer than the brachypterous females. It is likely that the similar longevity recorded for adult macropterous and brachypterous females is a consequence of the involvement and coordinative regulation by at least two different hormones ( $\mathrm{JH}$ and $\mathrm{AKH}$ ) in shortening the reproductive phase and post-OP periods of macropterous females. This attractive hypothesis is likely to be verified by future studies on $P$. apterus adults using cardiatectomy or transgene methods involving ablation of the corpus cardiacum (CC), the main source of AKH in Drosophila mutants.

Recently, Hodková \& Tatar (2011) discussed the endocrine mechanisms underlying the trade-off between lifespan and reproduction in the above two insects. Their study and review of the literature suggest that $\mathrm{JH}$ is a key mediator of this trade-off in insects. They show that in both insects adult diapause is associated with a lack of $\mathrm{JH}$ and retarded ageing, in which $\mathrm{JH}$ accelerates ageing and promotes reproduction, and that egg production is not likely to be the mechanism by which $\mathrm{JH}$ accelerates ageing. They suggest that processes, most probably occurring in the fat body, seem to mediate the effect of JH on longevity in these insects. The fat body appears to be a tissue that may potentially link CA-signalling and the physiological processes related to ageing in P. apterus females (Blazkova et al., 2011) since JH promotes the synthesis of vitellogenin in the fat body (Socha et al., 1991). It is reported that in Caenorhabditis elegans the antiDAF-16 represses vitellogenin mRNA and the knockout of the vitellogenin genes, and thus prolongs its lifespan (Murphy et al., 2003). The longevity of D. melanogaster is also extended by transgenic over-expression of the insulin signalling responsive transcription factor encoded by dFOXO in the fat body (Ginnakou et al., 2004; Hwangbo et al., 2004). However, it must be pointed out that AKHs, the hormones regulating mobilizations of energy reserves from the fat body and stimulating locomotion in various insects, including $P$. apterus (Socha et al., 1999; Kodrík et al., 2002a,b, 2010; Kodrík, 2008), 
might be also involved in coordinative endocrine regulation of ageing in insects. Defining the interactions between $\mathrm{JH}$ and $\mathrm{AKH}$ is likely to be the subject of the next phase in the study of the coordinative endocrine regulation of ageing in $P$. apterus and $D$. melanogaster.

ACKNOWLEDGEMENTS. This study was supported by the grant No. P 501/10/1215 from the Grant Agency of the Czech Republic and by the Institute of Entomology project No. Z50070508 obtained from the Academy of Sciences of the Czech Republic. The author thanks D. Rienesslová for her technical assistance.

\section{REFERENCES}

Barnes A.I. \& Partridge L. 2003: Costing reproduction. Anim. Behav. 66: 199-204.

Bell G. \& Koufopanou V. 1986: The cost of reproduction. In Dawkins R. \& Ridley M. (eds): Oxford Surveys in Evolutionary Biology, Vol. 3. Oxford University Press, Oxford, pp. 83-131.

BlANCKENHORN W.U. 1994: Fitness consequences of alternative life histories in water striders, Aquarius remigis (Heteroptera: Gerridae). - Oecologia 97: 354-365.

Blazková H., Provazník J. \& Hodková M. 2011: Novel roles for the corpus allatum hormone in the cost of sexual interactions in the linden bug, Pyrrhocoris apterus. - J. Insect Physiol. 57: 529-535.

De Loof A. 2011: Longevity and aging in insects: Is reproduction costly; cheap; beneficial or irrelevant? A critical evaluation of the "trade-of" concept. - J. Insect Physiol. 57: 1-11.

Denno R.F., Olmstead K.L. \& McLoud E.S. 1989: Reproductive cost of flight capability: a comparison of life history traits in wing dimorphic planthoppers. - Ecol. Entomol. 14: $31-44$.

FAIRBAIRN D.J. 1988: Adaptive significance of wing dimorphism in the absence of dispersal: a comparative study of the wing morphs in the water strider, Gerris remigis. - Ecol. Entomol. 13: $273-281$.

FlatT T. \& KAWECKI T.J. 2007: Juvenile hormone as a regulator of the trade-off between reproduction and life span of Drosophila melanogaster. — Evolution 61: 1980-1991.

FUJISAKI K. 1986: Reproductive properties of the oriental chinch bug, Cavelerius saccharivorus Okajima (Heteroptera: Lygaeidae), in relation to its wing polymorphism. - Res. Popul. Ecol. 28: 43-52.

GiLLOT C. 2003: Male accessory gland secretions: modulators of female reproductive physiology and behavior. - Annu. Rev. Entomol. 48: 163-184.

Ginnakou M.E., Goss M., Jünger M.A., Hafen E., Leevers S.J. \& Partridge L. 2004: Long-lived Drosophila with overexpressed dFOXO in adult fat body. - Science 305: 361.

HARRISON R.G. 1980: Dispersal polymorphisms in insects. Annu. Rev. Ecol. Syst. 11: 95-118.

Harshman L.G. \& Zera A.J. 2006: The cost of reproduction: the devil in the details. - Trends Ecol. Evol. 22: 80-86.

Herman W.S. \& Tatar M. 2001: Juvenile hormone regulation of longevity in the migratory monarch butterfly. - Proc. $R$. Soc. Lond. (B) 268: 2509-2514.

HodkovÁ M. 2008: Tissue signaling pathways in the regulation of life-span and reproduction in females of the linden bug, Pyrrhocoris apterus. — J. Insect Physiol. 54: 508-517.

Hodkoví M. \& Socha R. 2006: Endocrine regulation of the reproductive arrest in the long-winged females of a flightless bug, Pyrrhocoris apterus (L.) (Heteroptera: Pyrrhocoridae). - Eur. J. Entomol. 103: 523-529.
Hodková M. \& TAtar M. 2011: Parallels in understanding the endocrine control of lifespan with the firebug Pyrrhocoris apterus and the fruit fly Drosophila melanogaster. In Flatt T. \& Heyland A. (eds): Mechanisms of Life History Evolution. The Genetics and Physiology of Life History Traits and Trade-Offs. Oxford University Press, New York, pp. 171-179.

HonĚK A. 1976: Factors influencing the wing polymorphism in Pyrrhocoris apterus (Heteroptera, Pyrrhocoridae). - Zool. Jb. Syst. 108: 487-501.

HoNĔK A. 1985: Ecophysiological differences between brachypterous and macropterous morphs in Pyrrhocoris apterus (Heteroptera, Pyrrhocoridae). - Acta Entomol. Bohemoslov. 82: $347-354$.

Hwangbo D.S., Gershman B., Tu M.P., Palmer M. \& Tatar M. 2004: Drosophila dFOXO controls lifespan and regulates insulin signalling in brain and fat body. - Nature 429: 562-566.

Kisimoto R. 1965: Studies on the polymorphism and its role playing in the population growth of the brown planthopper, Nilaparvata lugens Stal. - Bull. Shikoku Agric. Exp. Stn. 13: $1-106$.

Kobayashi T. \& Osakabe M. 2009: Pre-vinter copulation enhances overwintering success of Orius females (Heteroptera: Anthocoridae). - Appl. Entomol. Zool. 44: 47-52.

KoDRíK D. 2008: Adipokinetic hormone functions that are not associated with insect flight. - Physiol. Entomol. 33: 171-180.

Kodrík D., Socha R. \& Zemek R. 2002a: Topical application of Pya-AKH stimulates lipid mobilization and locomotion in the flightless bug, Pyrrhocoris apterus (L.) (Heteroptera). Physiol. Entomol. 27: 15-20.

KodRík D., ŠIMEK P., LepŠA L. \& Socha R. 2002b: Identification of the cockroach neuropeptide Pea-CAH-II as a second adipokinetic hormone in the firebug Pyrrhocoris apterus. Peptides 23: 583-585.

Kodrík D., Socha R. \& Syrová Z. 2003: Developmental and diel changes of adipokinetic hormone in CNS and haemolymph of the flightless wing-polymorphic bug, Pyrrhocoris apterus. - J. Insect Physiol. 49: 53-61.

Kodrík D., Alquicer G. \& Socha R. 2010: Methoprene modifies adipokinetic hormone characteristics in the firebug Pyrrhocoris apterus (Heteroptera: Pyrrhocoridae). - Eur. J. Entomol. 107: 33-39.

Kubli E. 2003: Sex-peptides: seminal peptides of the Drosophila male. - Cell. Mol. Life Sci. 60: 1689-1704.

Maxová A., Kodrík D., Zemek R. \& Socha R. 2001: Diel changes in adipokinetic response and walking activity of Pyrrhocoris apterus (L.) (Heteroptera) in relation to physiological status and wing dimorphism. - Eur. J. Entomol. 98: 433-438.

Murphy C.T., McCarroll S.A., Bargmann C.I., Fraser A., Kamath R.S., Ahringer J. \& Kenyon C. 2003: Genes that act downstream of DAF-16 to influence the lifespan of Caenorhabditis elegans. - Nature 424: 277-284.

PARTRIDGE L. \& BARTON N.H. 1993: Optimality, mutation and the evolution of aging. - Nature 362: 305-311.

Pener M.P. 1972: The corpus allatum in adult acridids: the interrelation of its functions and possible correlations with the life cycle. In Hemming C.F. \& Taylor T.H.C. (eds): Proceedings of the International Study Conference on the Current and Future Problems of Acridology. Centre for Overseas Pest Research, London, pp. 135-147.

RANKIN M.A. \& BURChSTED J.C.A. 1992: The cost of migration in insects. - Annu. Rev. Entomol. 37: 533-539. 
RofF D.A. 1986: The evolution of wing dimorphism in insects. - Evolution 40: 1009-1020.

Rowe L. \& Scuder G.G.E. 1990: Reproductive rate and longevity in the water strider, Gerris buenoi. - Can. J. Zool. 68 99-102.

Sawby R., Klowden M.J. \& SJogren R.D. 1992: Sublethal effects of larval methoprene exposure on adult mosquito longevity. - J. Am. Mosq. Contr. 8: 290-292.

SLÁMA K. 1964: Hormonal control of respiratory metabolism during growth, reproduction, and diapause in female adults of Pyrrhocoris apterus L. (Hemiptera). - J. Insect Physiol. 10: 283-303.

SochA R. 1993: Pyrrhocoris apterus (Heteroptera) - an experimental model species: a review. - Eur. J. Entomol. 90 241-286.

SochA R. 2004: Decreased mating propensity of macropterous morph in flightless wing-polymorphic insect, Pyrrhocoris apterus (L.) (Heteroptera). - Eur. J. Entomol. 101: 539-545.

Socha R. 2006: Endocrine control of wing morph-related difference in mating success and accessory gland size in male firebugs. - Anim. Behav. 71: 1273-1281.

SocHA R. 2007: Factors terminating ovarian arrest in longwinged females of a flightless bug, Pyrrhocoris apterus (Heteroptera: Pyrrhocoridae). — Eur. J. Entomol. 104: 15-22.

SоснA R. 2008: Wing morph- and age-related differences in fertilization success of adult males of a flightless bug, Pyrrhocoris apterus (Heteroptera: Pyrrhocoridae). — Eur. J. Entomol. 105: 93-98.

Socha R. \& Hodková M. 2006: Corpus allatum volumedependent differences in accessory gland maturation in longand short-winged males of Pyrrhocoris apterus (Heteroptera: Pyrrhocoridae). - Eur. J. Entomol. 103: 27-32.

Socha R. \& Šula J. 1996: Differences in haemolymph proteins in relation to diapause and wing dimorphism in Pyrrhocoris apterus (Heteroptera: Pyrrhocoridae). - J. Comp. Physiol. (B) 166: 382-376.

Socha R. \& Šula J. 2006: Flight muscles polymorphism in a flightless bug, Pyrrhocoris apterus (L.): Developmental pattern, biochemical profile and endocrine control. - J. Insect Physiol. 52: 231-239.

Socha R. \& Šula J. 2008: Differential allocation of protein resources to flight muscles and reproductive organs in the flightless wing-polymorphic bug, Pyrrhocoris apterus. $-J$. Comp. Physiol. (B) 178: 179-188.

Socha R. \& ZeMEK R. 2000a: Wing movement behavior in longand short-winged morphs of flightless bug Pyrrhocoris apterus L. (Heteroptera: Pyrrhocoridae). - J. Insect Behav. 13: $741-750$.

Socha R. \& Zemek R. 2000b: Locomotor activity in adult Pyrrhocoris apterus (Heteroptera) in relation to sex, physio- logical status and wing dimorphism. - Physiol. Entomol. 25: 383-389.

Socha R. \& Zemek R. 2003: Wing morph-related differences in the walking pattern and dispersal in a flightless bug, Pyrrhocoris apterus (L.) (Heteroptera). - Oikos 100: 35-43.

Socha R. \& Zemek R. 2007: Temporal pattern of feeding activity in the firebug Pyrrhocoris apterus and its relation to sex, wing dimorphism and physiological state of adults. Physiol. Entomol. 32: 16-25.

Socha R., Šula J., KodRíK D. \& Gelbič I. 1991: Hormonal control of vitellogenin synthesis in Pyrrhocoris apterus (L.) (Heteroptera). - J. Insect Physiol. 37: 805-816.

Socha R., Šula J. \& ZemeK R. 1997: Feeding, drinking and digestive enzyme activities in long- and short-day females of Pyrrhocoris apterus (Heteroptera). - Physiol. Entomol. 22: 161-169.

Socha R., ŠUla J. \& ZemeK R. 1998: Feeding behaviour, digestive physiology and lipid content in macropterous females of Pyrrhocoris apterus (L.) (Heteroptera: Pyrrhocoridae). Physiol. Entomol. 23: 91-96.

Socha R., Kodrík D. \& Zemek R. 1999: Adipokinetic hormone stimulates insect locomotor activity. - Naturwissenschaften 88: $85-86$.

SteARns S.C. 1992: The Evolution of Life Histories. Oxford University Press, London, xii +249 pp.

TANAKA S. 1993: Allocation of resources to egg production and flight muscle development in a wing dimorphic cricket, Modicogryllus confirmatus. - J. Insect Physiol. 39: 493-498.

TAtar M. 2001: Senescence. In Fox C.W., Roff D.A. \& Fairbain D.J. (eds): Evolutionary Ecology: Concepts and Case Studies. Oxford University Press, New York, pp. 129-144.

Tatar M., Kopelman A., Epstein D., Tu M.P., Yin C.M. \& Carofalo R.S. 2001: A mutant Drosophila insulin receptor homolog that extends life span and impairs neuroendocrine function. - Science 292: 107-110.

Tatar M., BartKe A. \& Antebi A. 2003: The endocrine regulation of aging by insulin-like signals. - Science 299: 1346-1351.

Wigby S. \& Chapman T. 2005: Sex peptide causes mating costs in female Drosophila melanogaster. - Curr. Biol. 15: 316-321.

WiLliams T.D. 2005: Mechanisms underlying the costs of egg reproduction. - BioScience 55: 39-48.

YounG E.C. 1965: Flight muscle polymorphism in British Corixidae: ecological observations. - J. Anim. Ecol. 34: 353-390.

Zera A.J. \& Denno R.F. 1997: Physiology and ecology of dispersal polymorphism in insects. - Annu. Rev. Entomol. 42: 207-231.

Received June 25, 2012; revised and accepted July 18, 2012 